\title{
Desain Interior Kapal Navigasi S-126 untuk Meningkatkan Kualitas Keamanan, Kenyamanan, dan Memenuhi Standard Kode Kapal Yang Berlaku
}

\author{
Muthia Nur Amalina dan Thomas Ari Kristianto \\ Departemen Desain Interior, Fakultas Teknik Sipil dan Perencanaan, Institut Teknologi Sepuluh Nopember (ITS) \\ e-mail: muthia.nuramalina@gmail.com
}

\begin{abstract}
Abstrak-Sebagai negara kepulauan terbesar di dunia, yang memiliki 17.504 pulau yang membentang dari Sabang sampai Meraoke dengan panjang garis pantai kurang lebih $81.000 \mathrm{Km}$ serta luas wilayah laut sekitar 5,9 juta $\mathrm{Km}^{2}$. Indonesia memiliki potensi besar menjadi poros maritim dunia. Poros maritim merupakan sebuah gagasan strategis yang diwujudkan untuk menjamin konektifitas antar pulau, pengembangan industri perkapalan dan perikanan, perbaikan transportasi laut serta fokus pada keamanan maritim. Kapal perambuan dinilai sangat penting untuk mendukung upaya meningkatkan keselamatan dan keamanan pelayaran. Fungsi dan tugasnya sangat penting agar Sarana Bantu Navigasi Pelayaran (SBNP) tetap berkinerja baik dan andal. Kapal induk perambuan merupakan kapal negara kenavigasian yang memiliki fungsi untuk memasang pelampung suar serta melakukan pengangkutan dan pengangkatan. Selain itu, kapal perambuan disiapkan untuk berbagai aktivitas di menara suar. Dengan penjelasan diatas, penulis melihat besarnya peran desain interior dalam ikut serta membantu berkembangnya kapal kenavigasian di Indonesia, dengan tujuan meningkatkan kualitas keamanan kenyamanan dalam kapal, dan memenuhi standard kode kapal yang berlaku. Dengan meningkatnya kualitas desain interior yang mempengaruhi penggunanya, dapat meningkatkan kualitas hidup penggunanya juga. Selain itu, dengan karya Tugas Akhir ini penulis berharap dapat menginspirasi untuk perkembangan desain interior kapal kelas I kenavigasian di Indonesia.
\end{abstract}

Kata Kunci-Fungsional, Kapal Navigasi, Low Maintenance, Material.

\section{PENDAHULUAN}

I NDONESIA sebagai negara kepulauan terbesar di dunia, yang memiliki 17.504 pulau yang membentang dari Sabang sampai Meraoke dengan panjang garis pantai kurang lebih $81.000 \mathrm{Km}$ serta luas wilayah laut sekitar 5,9 juta $\mathrm{Km}^{2}$. Indonesia memiliki potensi besar menjadi poros maritim dunia. Poros maritim merupakan sebuah gagasan strategis yang diwujudkan untuk menjamin konektifitas antar pulau, pengembangan industri perkapalan dan perikanan, perbaikan transportasi laut serta fokus pada keamanan maritim.

Kapal induk perambuan merupakan kapal negara kenavigasian yang memiliki fungsi untuk memasang pelampung suar serta melakukan pengangkutan dan pengangkatan. Selain itu, kapal perambuan disiapkan untuk berbagai aktivitas di menara suar. Sarana dan prasarana kenavigasian dimaksud, antara lain meliputi tersedianya alur pelayaran yang aman dan efisien, tersedianya sarana bantu

navigasi pelayaran yang cukup dan handal, penyelenggaraan telekomunikasi pelayaran sesuai tuntutan dan peraturan internasional, serta penyediaan armada kapal negara kenavigasian yang handal. Pembangunan kapal induk perambuan adalah untuk mewujudkan keselamatan pelayaran di perairan Indonesia.

Banyak batasan yang ada dalam mendesain sebuah interior kapal, kapal memiliki batasan yang perlu diperhatikan, yaitu; memenuhi segala standar keamanan dalam kapal, luasan ruangan yang sangat terbatas sehingga perlu diperhatikannya tata letak furniture dan bentuk furniture itu sendiri sehingga ruangan memiliki luasan yang tetap nyaman, peletakan utilitas perkabelan yang rata-rata out bow juga harus disiasati sehingga interior terlihat nyaman, selain itu pola temperatur dalam kapal juga mengalami fluktuasi suhu karena faktor eksternal maupun internal kapal sehingga layouting dan pemilihan material untuk interior desain kapal perlu diperhatikan. Kebisingan dalam kapal juga dapat mempengaruhi kualitas penggunanya, sehingga dinding dalam kapal juga harus diberikan treatment sehingga dapat mengurangi kebisingan tersebut.

Dengan penjelasan diatas, penulis melihat besarnya peran desain interior dalam ikut serta membantu berkembangnya kapal kenavigasian di Indonesia, dengan tujuan meningkatkan kualitas keamanan kenyamanan dalam kapal, dan memenuhi standard kode kapal yang berlaku. Dengan meningkatnya kualitas desain interior yang mempengaruhi penggunanya, dapat meningkatkan kualitas hidup penggunanya juga. Selain itu, dengan karya Tugas Akhir ini penulis berharap dapat menginspirasi untuk perkembangan desain interior kapal kelas I kenavigasian di Indonesia.

\section{STUDI PUSTAKA}

\section{A. Kapal Navigasi}

Kapal Navigasi mempunyai tugas melakukan perencanaan, pengoperasian, pengadaan, dan pengawasan sarana bantu navigasi laut, survei hidografi, pemantauan alur dan perlintasan dengan menggunakan sarana instalasi untuk kepentingan keselmatan pelayaran. Kapal Kelas I Kenavigasianmempunyai tugas/misi antara lain: 
1. Melaksanakan pemasangan/pendistribusian pelampung suar pada wilayah operasinya.

2. Melakukan pengangkutan, pengangkatan, pemeliharaan/ perawatan pelampung suar beserta penjangkarannya.

3. Melaksanakan perawatan/ pemeliharaan rambu suar.

4. Melaksanakan perawatan/ pemeliharaan menara suar.

5. Mengantar gilir tugas penjaga menara suar dan keluarganya.

6. Melakukan pendistribusian perbekalan.

7. Melaksanakan tugas SAR dan tugas pemerintahan lainnya.

1) Ukuran Utama dan Kapasitas Kapal

Ukuran kapal:

- Panjang Keseluruhan (LOA) : $\pm 60.0 \mathrm{~m}$

- Panjang Perpendicular (LPP) : $\pm 54.0 \mathrm{~m}$

- Lebar (B) : $\pm 12.0 \mathrm{~m}$

- Tinggi $(\mathrm{H}): \pm 4.7 \mathrm{~m}$

- Sarat (T) : maksimum 3,5 m

- Vs 100\% MCR : 15 knot

- Jarak Jelajah Kapal : 4000 Nautical Mile

Ukuran utama kapal dan BHP tenaga mesin penggerak yang akan dicantumkan dalam kontrak harus ditentukan dari perhitungan Penyedia Jasa dengan persetujuan Pemberi Pekerjaan, dengan berpedoman pada kecepatan service (service speed condition) minimum 15 knot (pada 100\% Daya MCR), yang mana kecepatan ini harus dijamin oleh Penyedia Jasa.

\section{2) Kapasitas}

- Komplemen: 39 orang ( 25 crew kapal +14 crew dinas).

\section{B. Vibrasi dan Kebisingan pada kapal}

Getaran adalah gerakan bolak-balik yang ada di sekitar titik keseimbangan di mana kuat lemahnya dipengaruhi besar kecilnya energi yang diberikan. Pada dasarnya pada setiap kapal pasti mempunyai sumber getaran. Getaran paling besar terjadi pada ruang mesin. Hal tersebut dikarenakan pada ruang mesin terdapat mesin utama (Main Engine) yang bekerja sebagai penggerak utama kapal. Getaran pada kapal menghasilkan tingkat kebisingan yang bervariasi sesuai dengan jarak dari sumber getaran dan redaman yang menghalangi rambatan kebisingan dari sumber getaran.

Dalam interior, kebisingan dapat disiasati dengan treatment yang tepat, menurut Kristianto (2009) Beberapa teknik dalam desain interior yang dapat digunakan untuk meredam kebisingan antara lain; menggunakan material berpori (vinyl, woven wallpaper, ceiling gypsum), penggunaan pintu bersealant karet, pintu ganda, jendela dengan sealant, kaca dobel dengan cavity udara, furnitur tebal dan empuk dll. Pengendalian bunyi secara arsitektural disebut akustik lingkungan. Ia dapat membantu menciptakan suatu lingkungan, dimana kondisi mendengar secara ideal dapat tercipta. (Kristianto, 2009).

Dalam sebuah kapal kamar mesin merupakan tempat paling besar menghasilkan tingkat kebisingan paling tinggi. Hal ini disebabkan karena dalam kamar mesin terdapat mesin utama dengan daya besar dan sebagai penggerak utama kapal. Getaran yang dihasilkan oleh mesin utama menjadi kebisingan dengan tingkat tertentu. Adapun cara-cara untuk mencegah kebisingan yaitu membuat redaman untuk meminimalisir getaran yang ada.

Tabel 1.

Tingkat kebisingan disesuaikan dengan lama bekerja di tempat tersebut. Jika terlalu lama kita bekerja di tempat dengan tingkat

kebisingan tinggi maka akan terjadi resiko gangguan pendengaran.

\begin{tabular}{|c|c|}
\hline Tingkat Kebisingan & $\begin{array}{c}\text { Waktu maksimum bekerja dengan } \\
\text { tingkat kebisingan }\end{array}$ \\
\hline $82 \mathrm{~dB}$ & $16 \mathrm{jam} /$ hari \\
\hline $85 \mathrm{~dB}$ & $8 \mathrm{jam} / \mathrm{hari}$ \\
\hline $88 \mathrm{~dB}$ & $4 \mathrm{jam} / \mathrm{hari}$ \\
\hline $91 \mathrm{~dB}$ & $2 \mathrm{jam} / \mathrm{hari}$ \\
\hline $97 \mathrm{~dB}$ & $1 \mathrm{jam} / \mathrm{hari}$ \\
\hline $100 \mathrm{~dB}$ & $0,25 \mathrm{jam} / \mathrm{hari}$ \\
\hline
\end{tabular}

\section{Tingkat Kejenuhan Awak Kapal}

Secara harfiah, arti jenuh ialah padat atau penuh sehingga tidak mampu lagi memuat apa pun. Pengertian kejenuhan Menurut Muhibbin Syah (1999:161), jenuh dapat berarti jemu dan bosan dimana sistem akalnya tidak dapat bekerja sesuai dengan yang diharapkan dalam memproses item-item informasi atau pengalaman baru. Sedangkan secara harfiah jenuh ialah padat atau penuh sehingga tidak memuat apapun.

Dapat diambil kesimpulan bahwa kejenuhan adalah dimana kondisi emosional dan fisik seseorang yang tidak dapat memproses informasi - informasi atau pengalaman baru karena tekanan mendalam yang berkaitan dengan bekerja sehingga tidak bersemangat untuk melakukan aktivitas. kelelahan fisik dalam bekerja bisa menimbulkan kelelahan nonfisik atau mental. Mental orang tersebut direfleksikan dalam bentuk keluhan-keluhan.

Faktor - faktor yang menyebabkan kejenuhan awak kapal saat pelayaran:

1. Keterbatasan ruang dan fasilitas yang ada dalam kapal.

2. Durasi waktu dalam satu pelayaran.

3. Rutinitas pekerjaan dalam kapal.

4. Suasana interior dalam kapal tidak menyenangkan.

5. Kegiatan cenderung monoton.

Dari faktor di atas disebutkan bahwa lingkungan bekerja dapat menyebabkan kejenuhan. Lingkungan bekerja yang kurang nyaman dapat menyebabkan kejenuhan bekerja begitupula sebaliknya, lingkungan bekerja yang nyaman dapat membuat suasana kerja menjadi menyenangkan. Lingkungan yang nyaman dapat disiasati dengan memberikan gagasan- gagasan desain interior dalam elemen interior, maka peran desain interior cukup berpengaruh dalam mengatasi tingkat kejenuhan awak kapal dengan treatment yang tepat.

\section{Mendesain Interior Kapal}

Dalam mengkonsep desain kapal, Safety at Sea telah mendukung pengembangan dan verifikasi tujuan keamanan dalam kaitannya dengan stabilitas kapal, kerusakan, survivabilitas kapal, pemadam kebakaran, dan evakuasi. Tujuannya adalah untuk memastikan bahwa standar keselamatan sesuai dengan harapan keamanan modern. Selain 
itu analisis resiko juga penting dan pengkosepan desain kapal. Selama tahap awal konsep desain kapal, penggunaan analisis risiko menjadi banyak digunakan sebagai alat inovatif untuk mengevaluasi dan alternatif pengaturan terkait, tetapi tidak terbatas untuk stabilitas kerusakan dan masa hidup, perlindungan, serta pengaturan evakuasi kebakaran. Risiko desain dengan menggunakan analisis risiko eksplisit mendukung pengambilan keputusan desain.

Aspek terpenting dalam desain interior kapal yaitu memperhatikan detail furniture yang digunakan. Biasanya furniture yang digunakan merupakan custom made (bentuk dan ukuran sesuai permintaan dan disesuaikan dengan eksisting). Furniture harus menggunakan material yang ringan, water resistant, fire resistant dan mudah untuk di bongkar pasang. Selain itu, furniture harus memiliki fitur saving space mengingat keterbatasan luas ruangan dalam kapal. Untuk meningkatkan keamanan dan kenyamanan penggunaan fasilitas kapal, furniture yang digunakan dalam kapal harus menempel dengan dinding atau lantai yang telah ditentukan dalam general arrangement dengan mengkunci furniture dengan skrup atau mur khusus agar furniture tidak bergerak dalam keadaan kapal apapun.

\section{METODELOGI DESAIN}

\section{A. Metode Penelitian}

Penelitian ini dilakukan secara langsung oleh penulis di Galangan Kapal Orela Shipyard yang bertempat pada Jl. Raya Desa Ngimboh RT 02 RW 01, Ujung Pangkah Gresik. Waktu yang diambil untuk melakukan penelitian ini adalah hari Kamis, 21 September 2016, pada pukul 12.00-15.30 WIB.

Peneliti menggunakan penelitian kasus/lapangan yaitu meneliti dan mempelajari secara intensif latar belakang keadaan Kapal Navigasi. Sedangkan berdasarkan jenis data, penulis menggunakan jenis penelitian kualitatif. Penelitian kualitatif adalah pendekatan penelitian yang banyak dituntut menggunakan kalimat atau persepsi, mulai dari pengumpulan data, penafsiran terhadap data tersebut, serta penampilan hasilnya

Adapun langkah mendesain sebagai berikut:

\section{1) Pengumpulan data}

Teknik pengumpulan data yang diambil dalam penelitian ini adalah wawancara terhadap informan yang dibantu dengan pedoman interview bestandar dalam bentuk pertanyaan open ended (terbuka). Wawancara dilakukan 1- 2 kali dengan lamanya waktu bervariasi sesuai dengan situasu dan kondisi, serta berdasarkan kontrak yang telah disepakati.

Pada beberapa responden peneliti telah melakukan wawancara sejak pertemuan pertama saat penelitian karena peneliti dan responden sudah saling mengenal dan kontrak sudah dilakukan sejak studi pendahuluan. Berikut hasil wawancara yang telah dilakukan:

\section{2) Wawancara}

a) Hasil Wawancara dengan Nahkoda

\begin{tabular}{|c|c|}
\hline Pertanyaan & Jawaban \\
\hline \multirow[t]{2}{*}{$\begin{array}{l}\text { Apakah sarana dan } \\
\text { prasarana kapal ini } \\
\text { sudah lengkap? }\end{array}$} & $\begin{array}{l}\text { Sudah cukup lengkap, } \\
\text { yang terpenting bisa }\end{array}$ \\
\hline & $\begin{array}{l}\text { makan dan bisa tidur } \\
\text { dalam kapal sudah cukup. }\end{array}$ \\
\hline $\begin{array}{lr}\text { Apakah } & \text { fasilitas } \\
\text { yang } & \text { disediakan } \\
\text { disini } & \text { telah } \\
\text { memenuhi kebutuhan } \\
\text { aktivitas dalam kapal? }\end{array}$ & $\begin{array}{l}\text { Menurut saya sudah, segala yang } \\
\text { diperlukan saat berlayar sudah } \\
\text { tersedia dalam kapal ini. }\end{array}$ \\
\hline $\begin{array}{l}\text { Adakah saran } \\
\text { untuk desainer dalam } \\
\text { mendesain kapal ini? }\end{array}$ & $\begin{array}{l}\text { Untuk desainer, sarannya kalau } \\
\text { bisa suasana dalam kapal dibuat } \\
\text { rapih dan bersih kelihatannya, } \\
\text { lalu dibuat yang uptodate agar } \\
\text { kapal kita juga tidak kalah } \\
\text { dengan kapal buatan luar negeri. }\end{array}$ \\
\hline
\end{tabular}

b) Hasil Wawancara Crew

\begin{tabular}{|c|c|}
\hline Pertanyaan & Jawaban \\
\hline $\begin{array}{llr}\text { Apakah sarana } & \text { dan } \\
\text { prasarana kapal } & \text { ini } \\
\text { sudah lengkap? } & \end{array}$ & $\begin{array}{l}\text { Kurang lengkap sepertinya crew } \\
\text { kapal butuh ruangan untuk } \\
\text { hiburan dan bisa untuk bersantai } \\
\text { juga. }\end{array}$ \\
\hline $\begin{array}{lr}\text { Apakah } & \text { fasilitas } \\
\text { yang } & \text { disediakan } \\
\text { disini } & \text { telah } \\
\text { memenuhi kebutuhan } \\
\text { aktivitas dalam kapal? }\end{array}$ & $\begin{array}{l}\text { Sepertinya sudah, segala yang } \\
\text { diperlukan saat berlayar sudah } \\
\text { tersedia dalam kapal ini. }\end{array}$ \\
\hline $\begin{array}{l}\text { Adakah saran } \\
\text { untuk desainer dalam } \\
\text { mendesain kapal ini? }\end{array}$ & $\begin{array}{l}\text { Untuk desainer, sarannya kalau } \\
\text { bisa diakalin bagaimana } \\
\text { caranya } \\
\text { membuat suasana dalam kapal } \\
\text { terlihat selalu rapih dan bersih } \\
\text { gitu karena penggunanya sendiri } \\
\text { kan rata-rata lelaki semua pasti } \\
\text { berantakan kesannya. }\end{array}$ \\
\hline
\end{tabular}

B. Hasil Observasi Objek

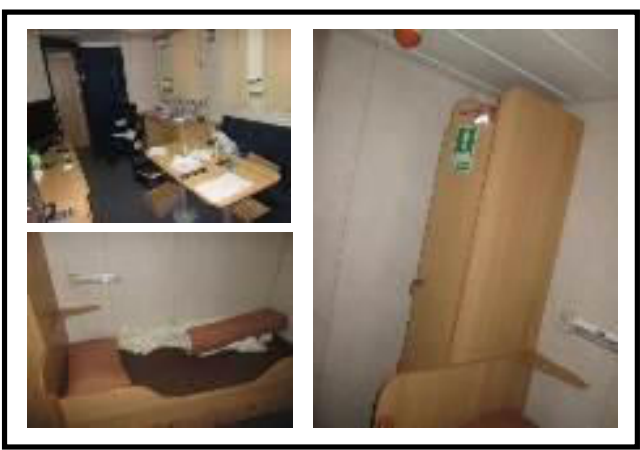

Gambar 1. Eksisting Captain room

Sumber: PT. Orela Shipyard (Akses: 17/12/2016 19:51 WIB. 
Foto diatas merupakan keadaan kamar tidur awak kapal dsalam Kapal Navigasi Bima Sakti. Dapat dilihat bahwa pengguna tidak merawat dan terkesan mengabaikan fasilitas yang disediakan.

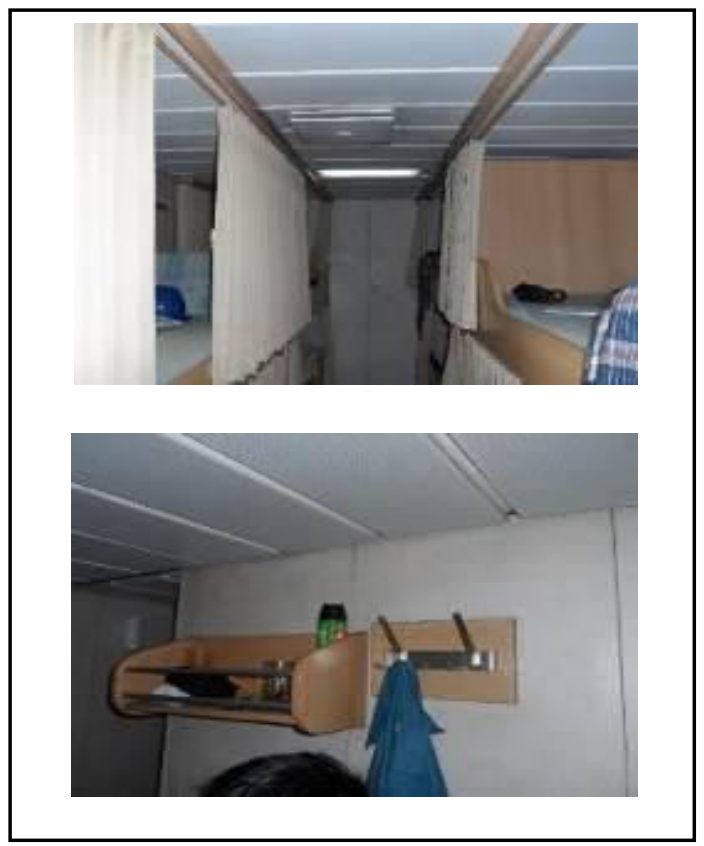

Gambar 2. Keadaan Crew room pada kapal.

Sumber: PT. Orela Shipyard (Akses: 17/12/2016 19:51 WIB)

Pada area kamar tidur bunker, ruangan terlihat sempit dan menumpuk dengan bentukan furniture yang ada membuat kesan ruangan menjadi lebih sempit, perlu diolahnya bentukan furniture dan menambahkan beberapa fasilitas guna memenuhi kebutuhan pengguna.

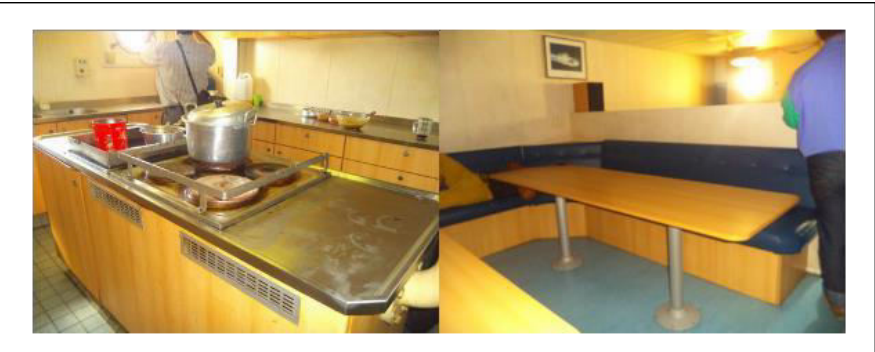

Gambar 3 Keadaan Crew room pada kapal

Sumber: PT. Orela Shipyard (Akses: 17/12/2016 19:51 WIB)

Pada area dapur dan tempat makan interiornya dirasa dapat lebih diolah dari segi furniture agar space kecil bisa dimanfaatkan dengan baik.

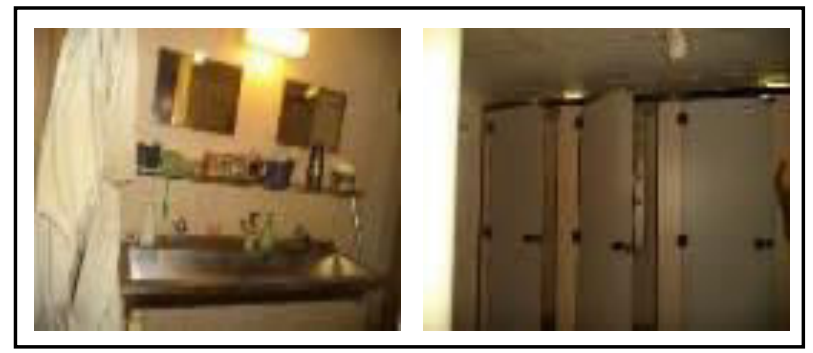

Gambar 4. Keadaan Kamar Mandi pada kapal.
Sumber: PT. Orela Shipyard (Akses: 17/12/2016 19:51 WIB)

Pada area kamar mandi sama seperti area sebelumnya bahwa dari segi suasana dapat diolah lebih agar memanfaatkan ruang kecil serta menambahkan beberapa fasilitas untuk memenuhi kebutuhan pengguna.

Dari Observasi yang telah dilakukan, ditemukan beberapa permasalahan yang ada dalam interior kapal;

1. Kurangnya Self-Awareness pada kebersihan dan kerapihan serta pemeliharaan fasilitas interior kapal.

2. Penggunaan warna dalam interior kapal terkesan monoton sehingga dapat mempengaruhi psikologi pengguna menjadi cepat jenuh.

3. Pemilihan material yang kurang bervariasi menyebabkan interior kapal terlihat kumuh.

\section{HASIL DESAIN}

\section{A. Captain room}

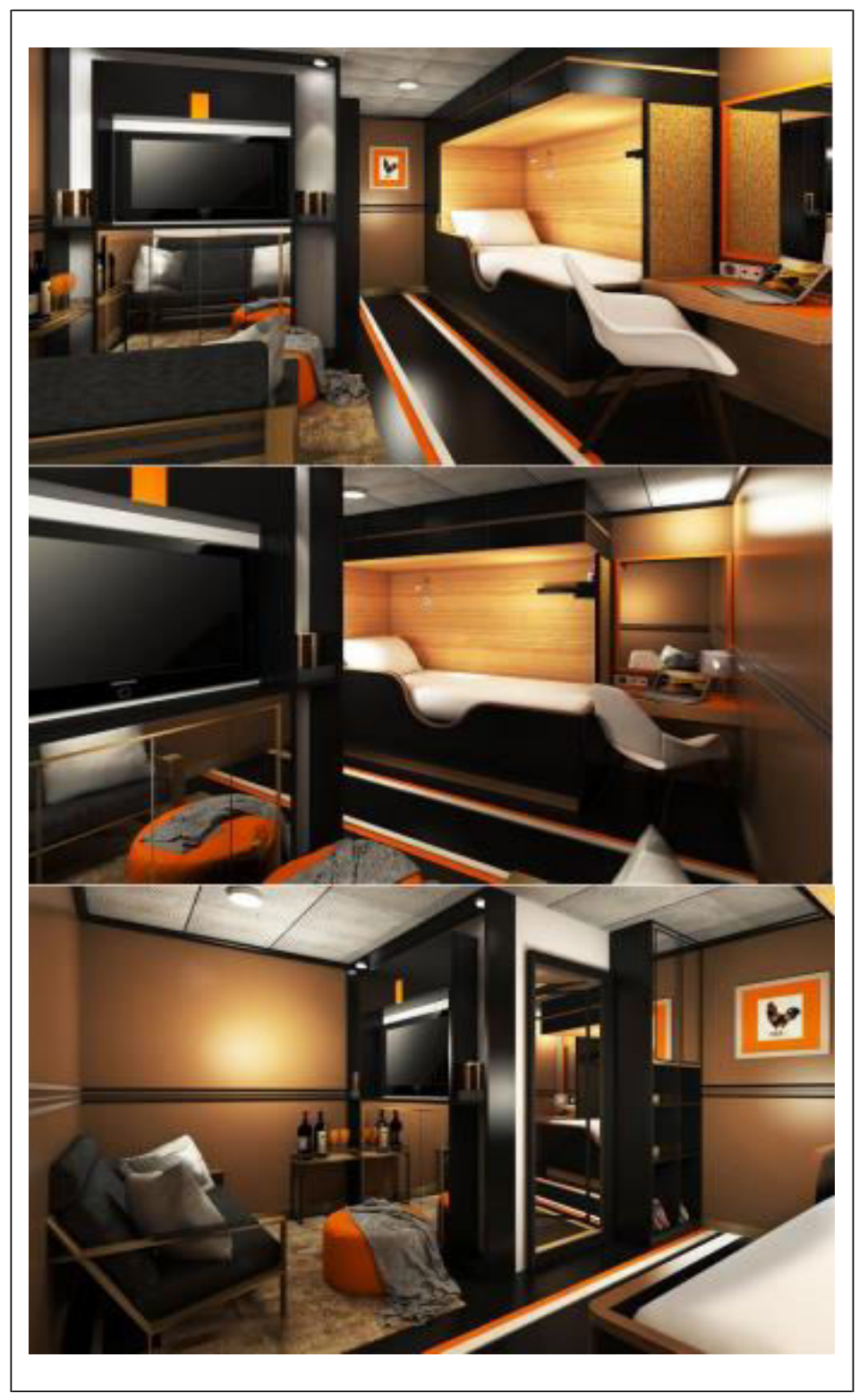

Gambar 5. Final desain Captain Room.

Sumber: Data pribadi (Penulis) (Akses: 17/12/2016 19:51 WIB) 
Pada desain interior captain room, sesuai dengan tema dan konsep yang ditentukan yaitu useful dan low maintenance menggunakan material pvc film board sebagai wall lining kapal, dan rubber vinyl pada lantainya. Dengan menggunakan warna gelap membuat suasana dalam kamar tersebut terlihat lebih nyaman dengan aksentuasi kuning menambah kesan segar dalam ruangan yang berwarna gelap. Selain itu, diberikan cermin pada beberapa sudut agar kamar terlihat lebih luas dan untuk pengguna merapikan diri.

\section{B. Mess Room}

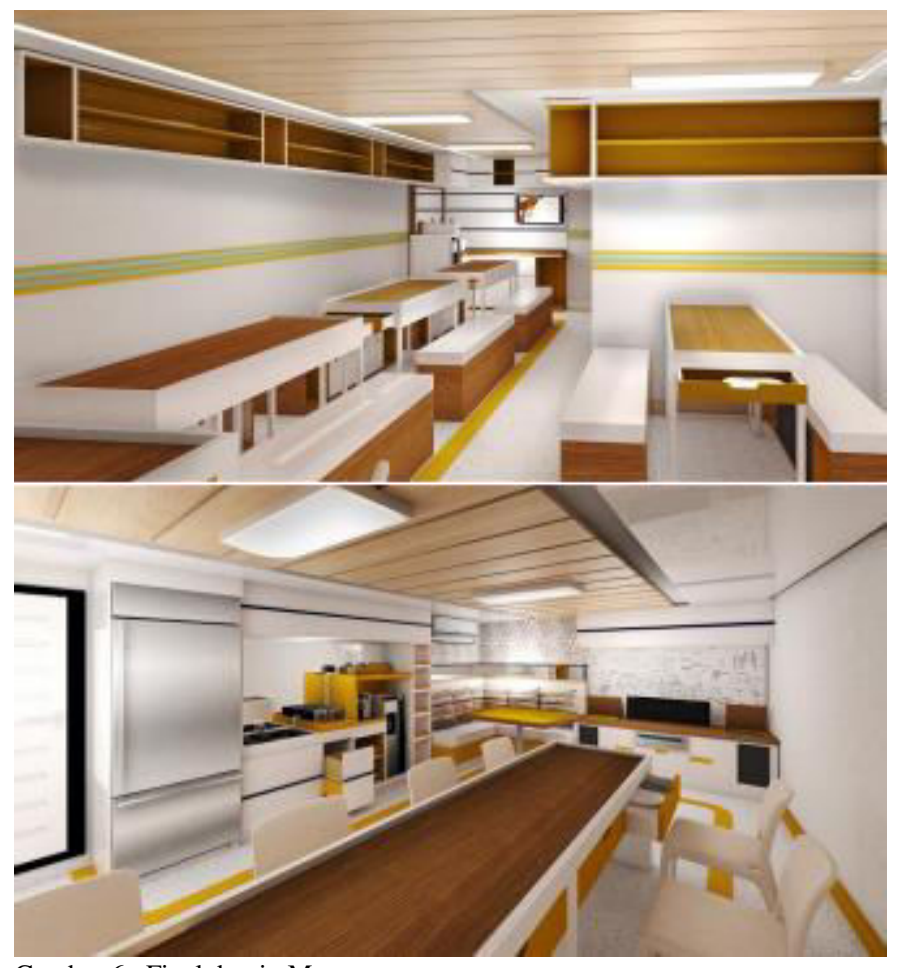

Gambar 6. Final desain Mess room.

Sumber: Data pribadi (Penulis) (Akses: 17/12/2016 19:51 WIB)

Ruangan mess room merupakan ruangan khusus yang berbeda dengan ruangan yang lainnya karena dalam ruangan ini lebih bersifat all purpose room salah satu kegunaannya selain tempat makan ialah entertaining dan meeting. Sesuai dengan tema interior yaitu Sleek-Minimalist, warna dominan dalam ruangan ini ialah putih dengan aksentuasi kuning. pada mess room diberikan warna aksentuasi kuning karena warna kuning memberi arti kehangatan dan rasa bahagia dan seolah ingin menimbulkan hasrat untuk bermain. Dengan kata lain warna ini juga mengandung makna optimis, semangat dan ceria. Dari sisi psikologi keberadaan warna kuning dapat merangsang aktivitas pikiran dan mental, yang diharapkan dapat mempengaruhi keadaan psikologi pengguna agar merasa lebih energize dan bersemangat.

Menurut Kristianto (2009) menerapkan warna dominan pada warna yang netral namun cukup hangat dan lembut (krem, abu-krem, putih, putih tulang, hijau muda, kuning muda). Selanjutnya ditempatkan warna berintensitas kuat hanya pada area tertentu dengan luasan sempit ( abu tua, coklat tua, burgundi, bitu tua, tosca, kayu dll.) dapat menyiasati suasana interior yang lebih seimbang. Selain itu pada bagian kanan kiri dinding ruangan ditambahkan storage lagi untuk memudahkan pengguna dalam meletakan barangnya.

\section{Wheel House (Ruang kemudi)}

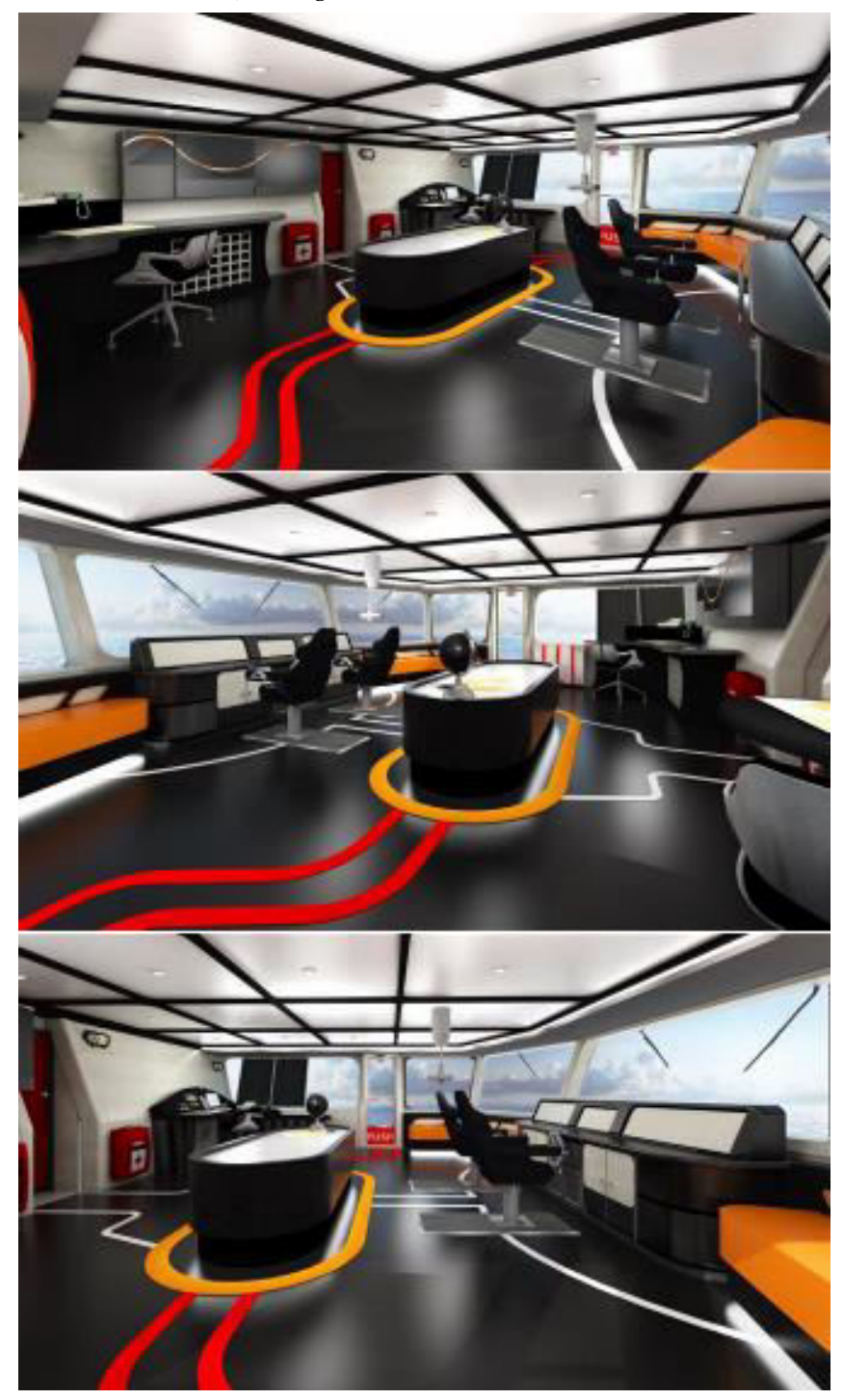

Gambar 7. Final desain Wheel House.

Sumber: Data pribadi (Penulis) (Akses: 17/12/2016 19:51 WIB)

Wheel house atau Anjungan adalah ruang komando kapal untuk menentukan dan mengatur posisi kapal yang terdapat roda kemudi dan alat kenavigasian yang dibutuhkan dalam pengoperasian kapal, di mana segala sesuatu yang berhubungan dengan kemudi kapal tersebut berada di dalam ruangan tersebut. Wheelhouse merupakan salah satu bagian yang terpenting di dalam sebuah kapal, dimana seluruh aktifitas yang berhubungan dengan kemudi dan navigasi kapal akan berlangsung di sana. Hal ini membuat wheel house harus di desain mengikuti standard dan aturan yang ada agar lebih aman dan nyaman untuk digunakan.

Desain yang diterapkan pada wheel house cenderung gelap karena letak wheel house di deck paling atas dan cenderung sangat terang maka interior menyeimbangkan dengan menggunakan material berwarna gelap. Pada panel kemudi dibuat melengkung agar tidak kaku, dan lebih dinamis dengan finishing gloss berwarna hitam dibagian yang meliputi roda kemudi kapal, peralatan navigasi, dan alat komunikasi kapal. Untuk ceiling diberikan border list berwarna hitam menjadi 
aksentuasi begitupula pengulangan di bagian meja radio, meja navigasi, dan meja peta. Pada meja peta dibuat banyak rak terbuka kotak-kotak gunanya untuk penyimpanan peta laut indonesia dengan digulung, untuk memudahkan pengguna dalam mencari peta. Lalu material finishing yang digunakan menggunakan solid surface yang glossy agar terlihat lebih luas karena pantulan dari bayangannya.

\section{KESIMPULAN}

Dengan hasil observasi dan wawancara diatas, penulis melihat besarnya peluang berkembangnya kapal kenavigasian di Indonesia, dengan tujuan negara Indonesia sebagai poros maritim dunia dibutuhkan kapal yang memenuhi standard dengan fasilitas yang lengkap dengan desain interior yang menarik, diharapkan dapat memberikan kesan berbeda dan nyaman untuk crew kapal sendiri. Selain itu, dengan menaikan standarisasi desain interior kapal, fasilitas yang disediakan kapal juga harus mengedukasi penggunanya agar pemakaian tidak gampang rusak dengan penggunaan material low maintenance di elemen interiornya agar ruangan dapat bekerja secara fungsional.

Secara garis besar, berikut poin-poin yang dapat diambil:

1. Banyaknya batasan dan masalah yang ada dalam kapal bukanlah menjadi hambatan dalam mendesain interior kapal, dengan material dan treatment desain yang benar dan memenuhi standard, akan membuat hasil desain yang sesuai.
2. Desain yang dibutuhkan oleh pengguna kapal ialah desain yang praktis, aman dan nyaman dan tidak melupakan unsur estetika.

3. Penggunaan furniture dalam kapal sebaiknya mengikuti standard teknis yang ada yaitu memiliki stopper pada bagian permukaan, dan memiliki kuncian ke dinding maupun lantai

\section{DAFTAR PUSTAKA}

[1] Direktorat Kenavigasian, D. J. (2016). SPESIFIKASI TEKNIS KAPALKELAS I KENAVIGASIAN. Indonesia.

[2] HUBLA, D. (2016, 07 16). Hublapedia. Diambil kembali dari DIRJEN HUBLA RESMIKAN PELUNCURAN 2 KAPAL KENAVIGASIAN: http://hubla.dephub.go.id/berita/Pages/DIRJEN-HUBLA-RESMIKANPELUNCURAN-2-KAPAL-KENAVIGASIAN.aspx

[3] Kristianto, T. A. (2009). Rancangan Ruang Praktik Nyaman Dari Aspek Desain Interior. Jurnal Desain Interior, 12.

[4] Lovely Lady, P. M. (2014). Kajian Kecelakaan Kapal di Pelabuhan Banten Menggunakan Human Factors Analysis and Classification System (HFACS). Jurnal Rekayasa Sistem Industri, 46-47.

[5] Sanjaya, R. (2012, April 1). Teknologi Kelautan. Diambil kembali dari DASAR ATURAN MENGENAI GETARAN DAN KEBISINGAN DI KAPAL: http://navale-engineering.blogspot.co.id/2012/04/dasar-aturanmengenai-getaran-dan.html

[6] World, M. (2010). Belajar dan Berbagi Informasi Pelayaran. Diambil kembalidari Hukum Maritim : http://www.maritimeworld.web.id/2010/11/peraturan-safety-of-life-atsea-solas.html

[7] Humas Laut. (2016). Dirjen Hubla Resmikan Peluncuran 2 Kapal Kenavigasiandirjen Hubla Resmikan Peluncuran 2 Kapal Kenavigasian. [Online].Tersedia:http://hubla.dephub.go.id/berita/Pages/DIRJENHUBLA -RESMIKAN-PELUNCURAN-2-KAPAL- KENAVIGASIAN.aspx[10 Desember 2016]. 